\title{
Cerebellopontine Angle Neoplasm
}

National Cancer Institute

\section{Source}

National Cancer Institute. Cerebellopontine Angle Neoplasm. NCI Thesaurus. Code C5414.

A neoplasm that affects the cerebellopontine angle. Representative examples include vestibular schwannoma and meningioma. 